\title{
THE ELASTICITY CHARACTERISTICS OF PALM DATE
}

\author{
M. I. Ghonimy* and M. A. Kassem ${ }^{* *}$
}

\begin{abstract}
The aim of this research work was to determine the physical and elasticity characteristics of date fruits (Phoenix dactylifera) cv Sukari. The physical characteristic included the date mass, volume, dimensions, moisture content, bulk density, flesh thickness, projected area, and elasticity of fruits, also seed mass and volume. Meanwhile, the elasticity characteristics of fruit included the stiffness coefficient (sc), bioyield stress ( $\sigma b)$, rupture stress ( $\sigma r)$ and Young's modulus of elasticity (E). The results showed that a good correlation was found between the sc and other properties; $\sigma b, \sigma r$ and $E$. Also, the average values of $s c, \sigma b$, $\sigma r$ and E were $0.017 \mathrm{~N} / \mathrm{mm}, 1158.3 \mathrm{~Pa}, 1485.9 \mathrm{~Pa}$ and $6.94 \mathrm{kPa}$ respectively.
\end{abstract}

Keywords: Date palm, physical characteristics, elasticity, Young's modulus, bioyield, rupture, stiffness and stress.

\section{INTRODUCTION}

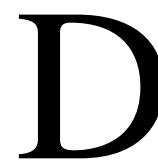
ate palm is one of the most important horticulture crops rich in vitamins. Date production in the world is only confined to a small number of countries, most of them being the Arab countries. Date palm is the economic crop in the kingdom Saudi Arabia, where production was approximately 968 thousand tons of dates (FAO 2008). It represents more than $15 \%$ of world production of dates. Also, the total cultivated area amounted to about 149 thousand hectares, representing $12.7 \%$ of the total cropped area in the kingdom. Sukari variety (صنف سكري) is the most important dates variety in Kingdom Saudi Arabia.

However, the date industry in the Arab world is not yet fully developed. Great efforts were carried out to evaluate the basic physical properties of some agricultural materials to point out their practical utility in machine structural design and food processes, Waziri and Mittal (1993).

\footnotetext{
*Prof., Ag. Eng. Dept., Fac. of Ag., Cairo University. ** Assoc. Prof., Ag. Eng. Dept., Fac. of Ag., Cairo University.
} 
There are several quality evaluations of date fruits. The physical and the mechanical characteristics are principal characteristics of the bioproduct. The stiffness is an engineering term when the evaluation is performed by mechanical tests.

Generally, the stiffness coefficient is the ratio of the force acting on a linear mechanical system, such as a spring, to its displacement from equilibrium Mohsenin (1970). Therefore, the stiffness is characterized by force- deformation curve.

Several investigators have studied the physical and mechanical characteristics of different agricultural and food materials.

Moustafa (2001) found that the physical and chemical characteristics of "Seewy date fruit were greatly influenced by pollen source and this effect varies according to the male parent used in pollination of female trees. Fecete (1994) found that the coefficient of elasticity for tomato and apple can be used to characterize the fruit firmness. Cenkowski et al. (1995) studied the effect of moisture sorption hysteresis on the mechanical behaviour of canola and showed that the modulus of elasticity of the product brought into equilibrium through adsorption was higher than that of the one obtained through desorption at the same moisture content. The other products whose mechanical properties have been studied include kiwi fruit (Abbott and Massie, 1995), apples (Abbott and Lu, 1996) and sea buckthorn berries (Khazaei and Mann, 2004). Anazodo and Chikwendu (1983) developed equations for the calculation of the Poisson's ratio and elastic modulus of circular bodies subjected to radial compression and Dinrifo and Faborode (1993) applied the Hertz's theory of contact stresses to cocoa pod deformation. Anazodo and Norris (1981) noted that the modulus of elasticity, crushing strength and modulus of toughness of corncob all decreased with moisture content.

Takao and Ohmori (1994) reported on the development of a handheld firmness tester. The tester measures the elastic deformation under a specific load and fruit firmness scaled between 0 and 100 based on the deformation measured. Timm et al. (1993) developed a portable instrument for measuring firmness of cherry fruit and various berries. Fruit is compressed between two flat plates and firmness is measured 
from the displacement of the moving plate for a pre-selected load. Prussia et al. (1994) developed a noncontact firmness device that used a laser displacement sensor to measure the amount of deflection (less than $1 \mathrm{~mm}$ ) at the product surface generated by a short puff of pressurized air. Mohsenin (1970) mentioned that the agriculture materials are of viscoelastic materials. Two models were used to describe the behavior of the agriculture materials. The first model is the Kelvin model where a spring and a damper are in parallel connection, while the second model is the Maxwell model where a spring and a damper are in serial connection. Also, the mentioned models are used to describe the deviation of the stress-strain curve of viscoelastic materials from that of ideal material

The aim of this research work was to investigate some physical and elasticity characteristics for date fruits (cv Sukari), that can be used in fruits handling and classifications.

\section{MATERIAL AND METHODS}

This study was carried out at the Faculty of Agriculture and Veterinary Medicine, Qassim University, KSA, during season 2010. Physical and elasticity characteristics of date fruits Sukari variety (Phoenix dactylifera) were determined at maturity level. Three different zones (Qassim, Riyadh and Al Ahsaa) famous in production of Sukari variety in KSA were studied. For each zone, 100 date fruits were randomly selected.

The dates were collected from different farms of the three regions. Dates were sorted to discard the damaged fruits, and immediately kept for less than $24 \mathrm{~h}$ in a cold store at $5^{\circ} \mathrm{C}$.

The following measurements and calculations were carried out:

\section{Date fruits dimensions (length and diameter)}

All dimensions of date fruit and seed were measured by Vernier calliper to an accuracy of $0.1 \mathrm{~mm}$.

\section{Date fruit moisture content}

The moisture content was determined for the flesh of dates using AOAC procedures $(A O A C, 1995)$. 


\section{Mass and bulk density}

The mass of date fruit was determined using a digital balance with an accuracy of $1.0 \mathrm{~g}$. The bulk density of date fruits was calculated using equation (1) by determining the mass of the date and its volume using a volumetric calibration.

$$
D_{b}=\frac{m}{V}
$$

Where:

$D_{b}=$ The bulk density of date fruit, $\mathrm{g} / \mathrm{cm}^{3}$;

$m=$ Mass of date fruit, $g$; and

$V=$ Volume of date fruit, $\mathrm{cm}^{3}$.

\section{Projected area of date fruit}

The projected area of date fruit was measured using digital planemeter, whose accuracy was $0.1 \mathrm{~cm}^{2}$.

\section{Elasticity characteristics of date fruit}

The date fruit was tested by an INSTRON- type testing machine gets damaged when measuring the force-deformation curve. However, with the pressure tests there is a range of elasticity in which the fruit is not damaged.

This system is the ideal system for tension and / or compression application in the case of biomaterials. The maximum force causing the compression is to $50 \mathrm{kN}$. The accuracy of the used INSTRON- type testing machine is to 0.001 Newton.

The Young's modulus of elasticity is a good measure of the elasticity of ideal materials. The behaviour of ideal materials is described by the Hooke's law and the model of which is a spring without damper.

The Young's modulus of elasticity $(E)$ for compressive stress is expressed by equation (2).

$$
E=\frac{\sigma}{\varepsilon}
$$

where:

$$
\begin{aligned}
& E=\text { Young's modulus of elasticity, } \mathrm{kPa} \\
& \sigma=\text { Compressive stress, } \mathrm{kPa} \\
& \varepsilon=\text { Specific strain, } \mathrm{mm} / \mathrm{mm}
\end{aligned}
$$




$$
\varepsilon=\frac{\Delta l}{l}
$$

Where:

$\Delta l=$ Variation in the length (deformation), $\mathrm{mm}$;

$l=$ Original length, $\mathrm{mm}$.

As it is shown the modulus of elasticity is a function of the original length, or size of the specimen tested.

Since the Young's modulus of elasticity in influenced by the length of the specimen, or the size (e.g. diameter) of the fruit, an other elastic characteristic should be introduced that is dependent on the deformation and independent on the length or size.

The stiffness coefficient $(s c)$ is the ratio of compressive force to the deformation.

The stiffness coefficient is expressed as follows:

$$
s c=\frac{F_{\mathrm{z}}}{z}
$$

Where:

$$
\begin{aligned}
& s c=\text { The stiffness coefficient }, \mathrm{N} / \mathrm{mm} \\
& F_{\mathrm{z}}=\text { The compressive force that occurs at " } z \text { " deformation of the } \\
& \quad \text { fruit, } \mathrm{N} ; \\
& z=\text { Deformation of the fruit, } \mathrm{mm} .
\end{aligned}
$$

RESULTS AND DISCUSSIONS

\section{Physical properties of date fruit}

The averages values of date fruit mass, flesh mass, seed mass, fruit volume, bulk density, moisture content, fruit length, fruit diameter, flesh thickness and projected area are shown in table (1).

From table (1) it is clear that the maximum values of fruit mass, flesh mass, fruit volume, fruit length, fruit diameter and flesh thickness were found at Qassim zone.

Data proved that the physical properties of date fruit were greatly influenced by planted zone. The Sukari Varity fruit mass for Qassim zone increased by about $9 \%$ compared to the date planted in Riyadh and Al Ahsaa zones. Not significant effect in fruit weight was produced Riyadh and Al Ahsaa zones. 
The present data clearly indicated that Qassim zone produced larger fruit volume compared in Riyadh and Al Ahsaa zones. However, not significant effect was found between Riyadh and Al Ahsaa zones. The increase in fruit volume was associated with the increase in fruit weight.

Also, the results in table (1) show that the higher values of CV (more than $10 \%$ ) were accompanied with the properties of fruit mass, seed mass, fruit volume and moisture content, while lower values of CV (less than $8 \%$ ) were obtained with flesh thickness, flesh mass, bulk density, dimensions, projected area and seed volume of date fruit. A statistical analysis (ANOVA at 5\% level) showed significant differences for every property except the seed mass, seed volume and the bulk density of date fruits.

Table 1. Physical properties of the Sukari Varity date fruits

\begin{tabular}{|c|c|c|c|c|c|c|}
\hline \multirow{2}{*}{ Property } & \multicolumn{2}{|c|}{ Qassim } & \multicolumn{2}{|c|}{ Riyadh } & \multicolumn{2}{|c|}{ Al Ahsaa } \\
\hline & $\begin{array}{c}\text { Mean } \\
\text { value }^{(a)}\end{array}$ & $C V^{(\mathbf{b})}$ & $\begin{array}{c}\text { Mean } \\
\text { value }^{(a)}\end{array}$ & $\mathbf{C V}^{(\mathbf{b})}$ & $\begin{array}{c}\text { Mean } \\
\text { value }^{(a)}\end{array}$ & $\mathbf{C} \mathbf{V}^{(\mathbf{b})}$ \\
\hline Fruit mass, $\mathrm{g}$ & $13.8 \mathrm{~A}$ & 12.3 & $12.9 \mathrm{~B}$ & 10.7 & $12.7 \mathrm{~B}$ & 10.1 \\
\hline Flesh mass, $\mathrm{g}$ & $10.4 \mathrm{~A}$ & 1.3 & $9.9 \mathrm{~B}$ & 1.5 & $9.8 \mathrm{C}$ & 1.9 \\
\hline Seed mass, $\mathrm{g}$ & $2.2 \mathrm{~A}$ & 10.0 & $2.1 \mathrm{~A}$ & 11.3 & $2.2 \mathrm{~A}$ & 10.1 \\
\hline Fruit volume, $\mathrm{cm}^{3}$ & $12.8 \mathrm{~A}$ & 10.2 & $12.1 \mathrm{~B}$ & 12.4 & $12.2 \mathrm{~B}$ & 10.1 \\
\hline Seed volume, $\mathrm{cm}^{3}$ & $2.1 \mathrm{~A}$ & 4.6 & $2.2 \mathrm{~A}$ & 6.4 & $2.1 \mathrm{~A}$ & 5.3 \\
\hline Fruit bulk density, g.cm $^{-3}$ & $0.97 \mathrm{~A}$ & 3.1 & $0.98 \mathrm{~A}$ & 4.2 & $0.97 \mathrm{~A}$ & 2.6 \\
\hline Fruit moisture content, \% & $31.1 \mathrm{~A}$ & 10.5 & $31.9 \mathrm{~B}$ & 11.4 & $32.8 \mathrm{C}$ & 8.9 \\
\hline Fruit length, mm & $32.8 \mathrm{~A}$ & 5.9 & $30.4 \mathrm{~B}$ & 4.6 & $28.3 \mathrm{C}$ & 3.8 \\
\hline Fruit diameter, mm & $23.1 \mathrm{~A}$ & 6.4 & $18.4 \mathrm{~B}$ & 5.6 & $18.9 \mathrm{~B}$ & 5.9 \\
\hline Flesh thickness, mm & $8.0 \mathrm{~A}$ & 6.1 & $7.6 \mathrm{~B}$ & 7.8 & $7.0 \mathrm{C}$ & 4.6 \\
\hline Projected area, $\mathrm{cm}^{2}$ & $5.62 \mathrm{~A}$ & 4.2 & $5.42 \mathrm{~B}$ & 3.7 & $5.40 \mathrm{~B}$ & 4.6 \\
\hline
\end{tabular}

(a) Mean values with different letters are significantly different (Duncan test $5 \%$ level).

(b) CV Coefficient of variation (Standard deviation divided by the mean value).

\section{Elasticity characteristics of date fruit}

\subsection{Stress $(\sigma)$ - Strain $(\varepsilon)$ curve}

Figure (1) shows the stress strain curve of date palm (Sukari variety) under different studied zones. It is clear that before the point called proportional limit, the stress-strain curve is a straight line. Generally, the elastic limit is the limit beyond which the date will no longer go back to 
its original shape when the load is removed, or it is the maximum stress that may be developed such that there is no permanent when the load is entirely removed. The elastic limit of Sukari variety ranged from 765.4 $\mathrm{Pa}$ to $1020.5 \mathrm{~Pa}$, while the average value for different studied zones was 892.9Pa. Also, from the calculated results of Young's modulus of elasticity $(E)$ for date fruits at different studied zones showed that the $E$ values ranged from $3.71 \mathrm{kPa}$ to $9.97 \mathrm{kPa}$, while the average value for different studied zones was $6.97 \mathrm{kPa}$

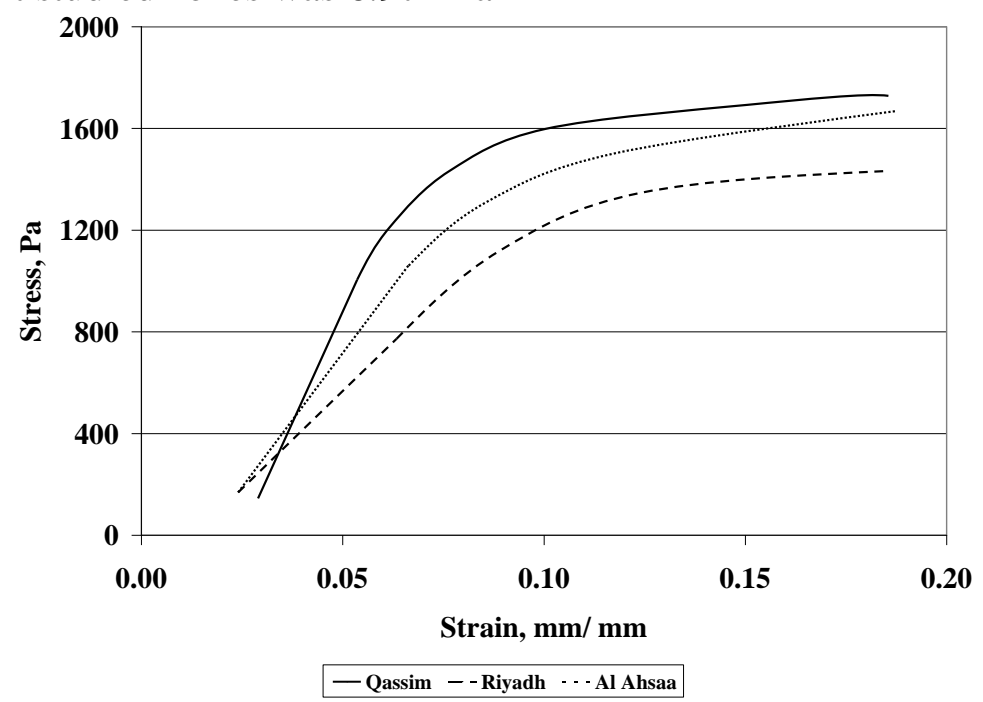

Fig. 1. Stress- strain curve of date pale sukari variety under different studied zones.

\section{2 Stiffness coefficient ( $s c)$}

In general, the stiffness coefficient $(s c)$ was calculated for the data measured by the INSTRON- type testing machine. The average values of the stiffness coefficient ( $s c$ ) for Sukari variety date palm for the studied zones are shown in fig. (2).

From fig. (2), it is clear that the maximum value of stiffness coefficient, $0.17 \mathrm{~N} / \mathrm{mm}$, was found for Riyadh and Al Ahsaa zones at 1020.74 Pa compressive stress. At $255.19 \mathrm{~Pa}$ compressive stress, the average values of $s c$ were $0.08 \mathrm{~N} / \mathrm{mm}$ for all studied zones. At $510.37 \mathrm{~Pa}$ compressive stress, the average values of $s c$ were $0.14,0.15$ and $0.13 \mathrm{~N} / \mathrm{mm}$ for Qassim, Riyadh and Al Ahsaa zones respectively. At $765.56 \mathrm{~Pa}$ 
compressive stress, the average values of $s c$ were $0.14,0.16$ and 0.14 N/mm for Qassim, Riyadh and Al Ahsaa zones respectively

Analysis of variance (ANOVA) was done using SPSS program.

The results of the statistical analysis (ANOVA) are illustrated in table (2).

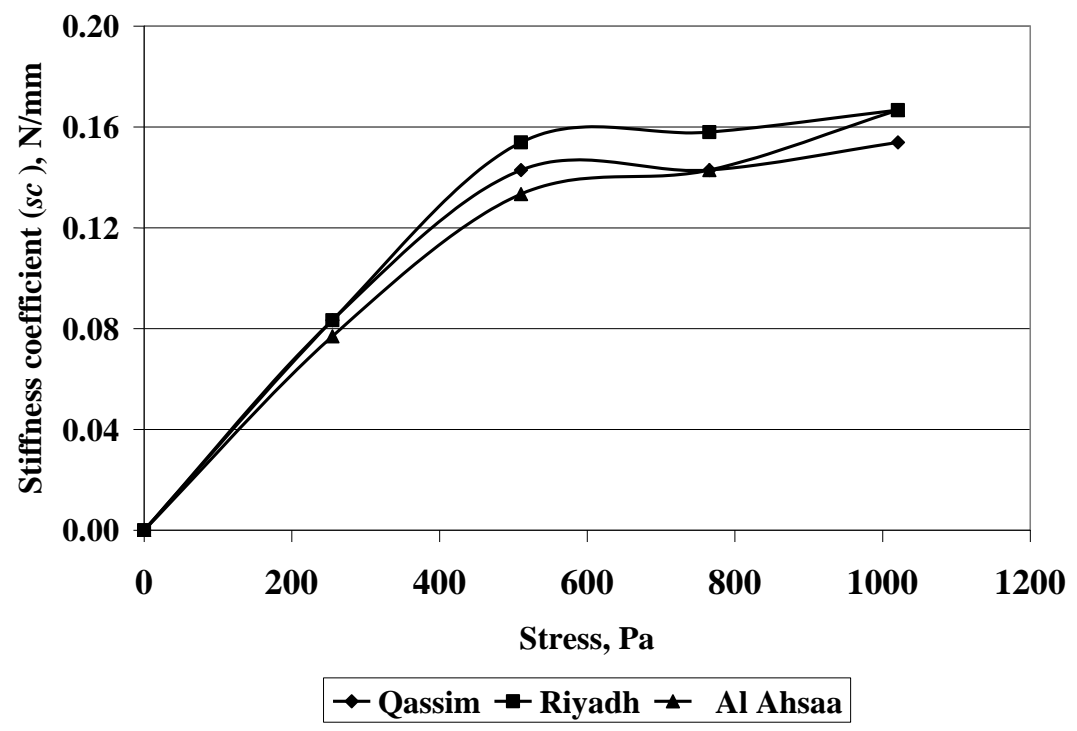

Fig.2. The relation between the compressive stress and stiffness coefficient for date palm ( $c v$ Sukari) under different studied zones.

Table 2. The analysis of variance (ANOVA) for the effect of studied factors on the stiffness coefficient.

\begin{tabular}{||l||c|c|c||}
\hline \multicolumn{1}{|c||}{ Source of Variation } & DF & Mean Square & Sig. of (F) \\
\hline \hline Replication & 9 & $3.6 \mathrm{E}-08$ & \\
Studied zones (z) & 2 & $5.8 \mathrm{E}-07$ & $* *$ \\
Stress (s) & 3 & $5.2 \mathrm{E}-04$ & $* *$ \\
z x s & 6 & $6.2 \mathrm{E}-07$ & $* *$ \\
Error & 99 & $3.4 \mathrm{E}-08$ & \\
\hline \hline Total & 119 & & \\
\hline
\end{tabular}

** Indicate highly significant mean square at $1 \%$ level of probability.

From table (2), its clear that the effect of studied zones (Qassim, Riyadh and Al Ahsaa) and compressive stress on the stiffness coefficient (sc) 
was highly significant at 0.01 level of probability, i.e. the stiffness coefficient is highly affective by the difference of the studied factors.

Figures 3, 4 and 5 represent the stiffness coefficient (sc) for Sukari variety at Qassim, Riyadh and Al Ahsaa zones respectively. From figures 2,3 and 4 it is clear that the $s c$ increased by increasing the bioyield $(\sigma b)$ stress (ranging from 1006.4 to $1275.6 \mathrm{~Pa}$ ), while the $s c$ was decreased by increasing the rupture $(\sigma r)$ stress (ranging from 1265.4 to $1667.9 \mathrm{~Pa}$ ).

From fig. 3, the stiffness coefficient ( $s c$ ) was analyzed as a function of the bioyield $(\sigma b)$ and rupture $(\sigma r)$ stresses for date fruits at Qassim zone. The probability level was found to be $1.0 \%$ for bioyield stress and 5.0\% for the rupture stress. The results of statistical analysis showed that the effect of $\sigma b$ and $\sigma r$ on the $s c$ were highly significant.

Regression approach was used to derive regression equations (5 and 6), expressing the effects of bioyield and rupture stress on the stiffness coefficient (sc) for date palm ( $c v$ Sukari) under Qassim zone.

For bioyield stress $(\sigma b), s c=1 \mathrm{E}-05 \sigma b+0.0012 \quad \ldots .(5), \mathrm{R}^{2}=0.979$

For rupture stress $(\sigma r), s c=-5 \mathrm{E}-06 \sigma r+0.0244 \ldots \ldots(6), \mathrm{R}^{2}=0.720$

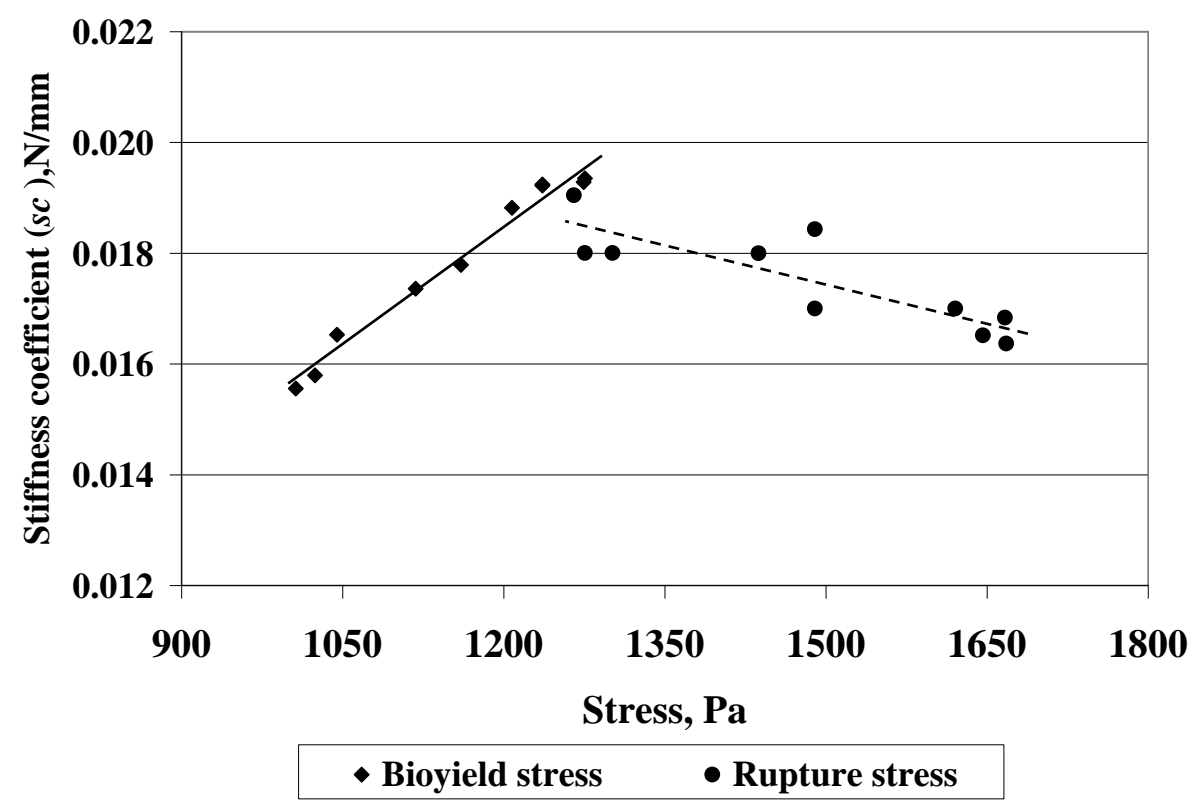

Fig. 3. Stiffness coefficient (sc) versus the stress for date palm ( $c v$ Sukari) under Qassim zone. 
The stiffness coefficient ( $s c$ ) was analyzed as a function of the bioyield $(\sigma b)$ and rupture $(\sigma r)$ stresses for date fruits at Riyadh zone (Fig. 4). The probability level is $5.0 \%$ for both cases. The results of statistical analysis showed that the effect of $\sigma b$ and $\sigma r$ on the $s c$ were significant.

Regression approach was used to derive a regression equations (7 and 8), expressing the effects of bioyield and rupture stress on the stiffness coefficient (sc) for date palm ( $c v$ Sukari) under Riyadh zone.

For bioyield stress $(\sigma b), s c=1 \mathrm{E}-05 \sigma b+0.0025 \quad \ldots \ldots \ldots(7), \mathrm{R}^{2}=0.752$

For rupture stress $(\sigma r), s c=-9 \mathrm{E}-06 \sigma r+0.0316$ (8), $\mathrm{R}^{2}=0.799$

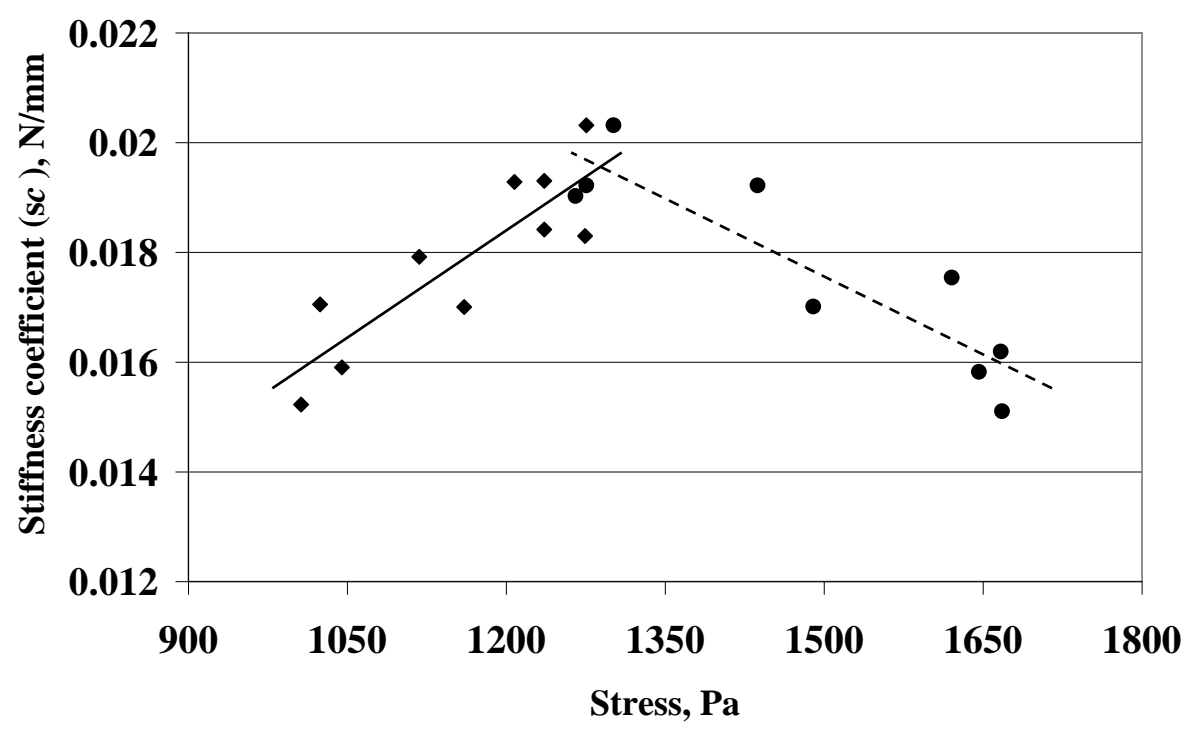

\section{- Bioyield stress • Rupture stress}

Fig. 4. Stiffness coefficient (sc) versus the stress for date palm ( $c v$ Sukari) under Riyadh zone.

The stiffness coefficient $(s c)$ was analyzed as a function of the bioyield $(\sigma b)$ and rupture $(\sigma r)$ stresses for date fruits at Al Ahsaa zone (Fig. 5). The probability level is $5.0 \%$ for both cases. The results of statistical analysis showed that the effect of $\sigma b$ and $\sigma r$ on the $s c$ were significant. 
Regression approach was used to derive regression equations (9 and 10), expressing the effects of bioyield and rupture stress on the stiffness coefficient (sc) for date palm ( $c v$ Sukari) under Al Ahsaa zone.

For bioyield stress $(\sigma b), s c=1 \mathrm{E}-05 \sigma b+0.0065$ (9), $R^{2}=0.763$

For rupture stress $(\sigma r), s c=-7 \mathrm{E}-06 \sigma r+0.0285$ (10), $R^{2}=0.634$

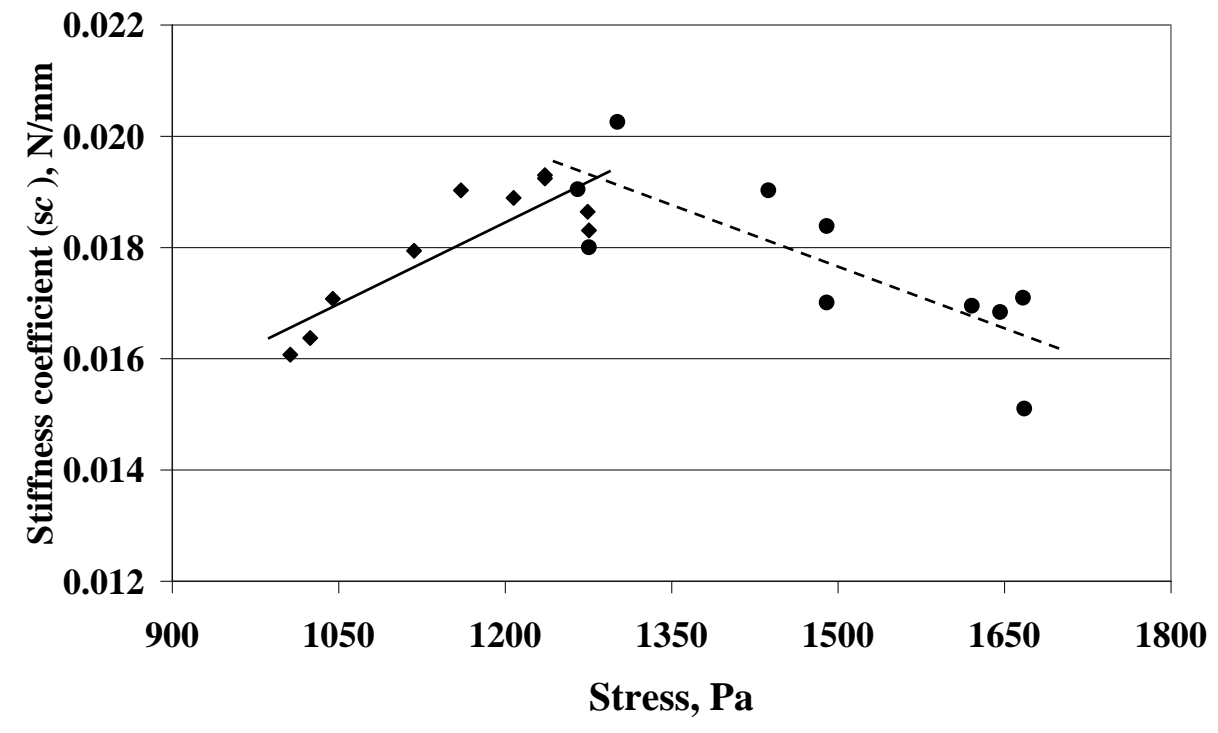

\section{- Bioyield stress $\quad$ Rupture stress}

Fig. 5. Stiffness coefficient (sc) versus the stress for date palm ( $c v$ Sukari) under Al Ahsaa zone.

From the previous results, regression approach was used to derive a regression equation (11 and 12), expressing the effects of bioyield and rupture stress on the stiffness coefficient (sc) for date palm ( $c v$ Sukari) under different studied zones.

For bioyield stress $(\sigma b), s c=1 \mathrm{E}-005 \sigma b+0.0034 \ldots \ldots \ldots(11), \mathrm{R}^{2}=0.816$

For rupture stress $(\sigma r), s c=-7 \mathrm{E}-06 \sigma r+0.0281 \ldots \ldots \ldots(12), \mathrm{R}^{2}=0.696$

Also, the stiffness coefficient (sc) was analyzed as the function of the Young's modulus of elasticity $(E)$ for date fruits at different studied zones (Fig. 6). The probability level is $1.0 \%$ for both zones. The results of statistical analysis showed that the effect of $E$ on the $s c$ were highly significant. 
Regression approach was used to derive regression equation (13, 14 and $15)$, expressing the effects of Young's modulus of elasticity $(E)$ on the stiffness coefficient (sc) for date palm ( $c v$ Sukari) under different zones. For Qassim zone, $s c=0.0018 E+0.0026 \quad \ldots \ldots \ldots .(13), \mathrm{R}^{2}=0.9319$ For Riyadh zone, $s c=0.0027 E+0.0003 \ldots \ldots \ldots .(14), \mathrm{R}^{2}=0.9826$ For Al Ahsaa zone, $s c=0.0025 E+0.0008$ (15), $R^{2}=0.9634$

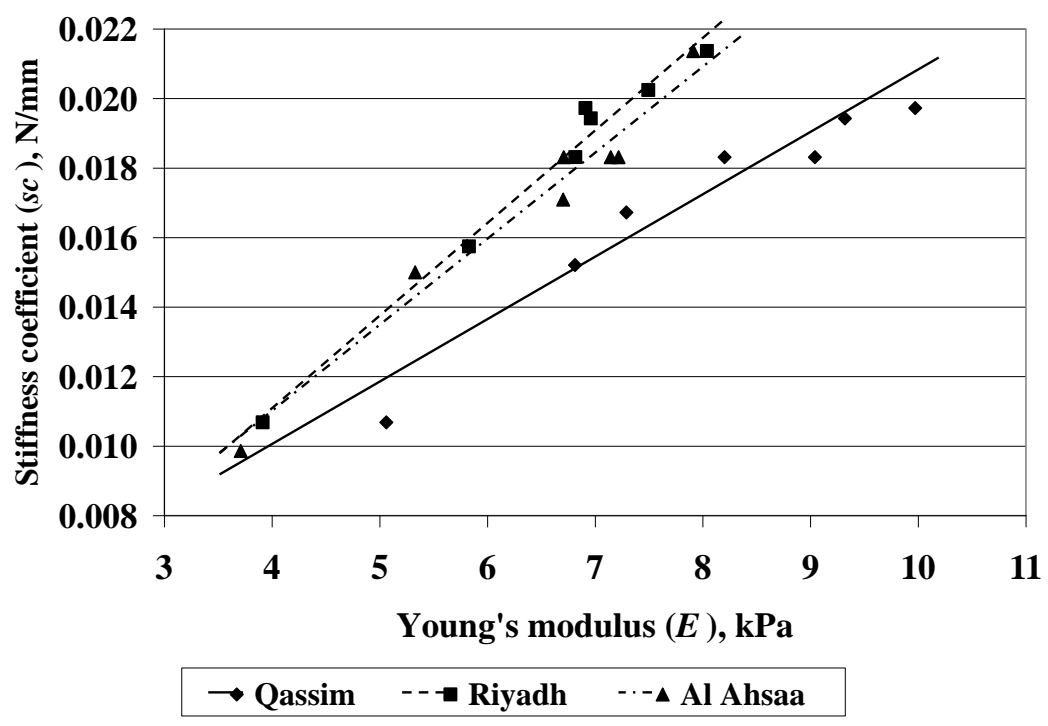

Fig. 6. Stiffness coefficient (sc) versus Young's modulus of elasticity $(E)$ for date palm ( $c v$ Sukari) under different studied zones.

From figures 3, 4, 5 and 6 it can be found that, the range and average values of date palm characteristics are illustrated in table 3 .

Table 3. The range and average values of the elastic characteristics of date palm (Sukari variety)

\begin{tabular}{|l|c|c|c|}
\hline \multirow{2}{*}{ Characteristics } & \multirow{2}{*}{ Range } & \multicolumn{2}{c|}{ Average } \\
\cline { 3 - 4 } & & Value & $\mathrm{CV}$ \\
\hline Bioyield stress, $\mathrm{Pa}$ & $1024.4-1224.4$ & 1158.3 & 7.76 \\
\hline Rupture stress, $\mathrm{Pa}$ & $1265.4-1667.9$ & 1485.9 & 8.49 \\
\hline Elastic limit, $\mathrm{Pa}$ & $765.4-1020.5$ & 892.9 & 3.6 \\
\hline Young's modulus, $\mathrm{kPa}$ & $3.71-9.97$ & 6.97 & 16.3 \\
\hline Stiffness coefficient, N/mm & $0.010-0.021$ & 0.017 & 7.02 \\
\hline
\end{tabular}




\section{CONCLUSION}

From this investigation the following conclusions can be done:

1. There are significant differences between different zones date fruits for each of fruit mass, flesh mass, fruit volume, fruit moisture content, fruit dimensions, flesh thickness and fruit projected area.

2. There are no significant differences between different zones date fruits for each of seed mass, seed volume and fruit bulk density.

3. The stiffness coefficient shows a good correlation between the bioyield stress at Qassim zone and an acceptable correlation at the other zones.

4. The stiffness coefficient shows an acceptable correlation with the rupture stress at different studied zones.

5. A good correlation was found between the stiffness coefficient and the Young's modulus of elasticity.

\section{REFERENCES}

Abbott, J. A. and D. R. Massie. 1995. Non-destructive dynamic force/deformation measurement of kiwifruit firmness (Actinidia Delicious). Transactions of the ASAE, 38(6): 1809 - 1812.

Abbott, J. A. and R. Lu. 1996. Anistropic mechanical properties of apples. Transactions of the ASAE, 39(4): 1451 - 1459.

Anazodo, U. G. N. and E. R. Norris. 1981. Effects of genetic and cultural practices on the mechanical properties of corncobs. Journal of Agricultural Engineering Research, 26: 97 - 107.

Anazodo, U. G. N. and S. C. Chikwendu. 1983. Poisson's ratio and elastic modulus of radially compressive biomaterials - I: small deformation approximation. Transactions of the ASAE, 26(3): 923 929.

AOAC. 1995. Official methods of analysis $\left(16^{\text {th }}\right.$ ed.). Association of Official Analytical Chemists. Washington, DC.

Balls, R. C. 1995. Horticultural Engineering Technology. Published by MacMillan Publishers ltd, U.K. 
Cenkowski, S., Q. Zhang and W.J. Crerar. 1995. Effect of sorption hysteresis on the mechanical behaviour of canola. Transactions of the ASAE, 38(5): 1455 - 1460.

Dinrifo, R. R. and M. A. Faborode. 1993. Application of Hertz's theory of contact stresses to cocoa pod deformation. Journal of Agricultural Engineering and Technology, 1: 63 - 73.

FAO. 2008. Food and Agriculture Organization of the United Nations. http://faostat.fao.org/site/567/DesktopDefault.aspx?PageID=567

Fecete, A. 1994. Elasticity characteristics of fruits. International Agrophysics, 8(3): 411- 414.

Khazaei, J. and D. D. Mann. 2004. Effects of temperature and loading characteristics on mechanical and stress relaxation properties of sea buckthorn berries, Part 1: compression tests. Agricultural Engineering International Ejournal, Manuscript FP 03 011, http//cigr-ejournal.tamu.edu/html/Volume 6, April.

Mohsenin, N. N. 1970. Physical Properties of Plant and Animal Materials. Gordon and Breach Sc. Pub., N. Y.

Moustafa, A. A. 2001. The effect of pollen source of fruit characteristics of Seewy date cultivar. $2^{\text {nd }}$ conf. on Date Palms (Al-Ain, UAE, March 25-27, 2001)

Prussia, S. E., J. J. Astelford, B. Hewlett, and Y. C. Hung. 1994. Nondestructive firmness measuring device. U.S. Patent No. 5,372,030.

Takao, H. and Ohmori. 1994. Nondestructive hardness meter for fruit. In nondestructive quality evaluation of horticultural crops, Proc. 24th Int. Hort. Cong., Kyoto, Japan, 34-51. G. G. Dull, M. Iwamoto, and S. Kawano, eds. Tokyo, Japan: Saiwai Shobou Publisher.

Timm, E. J., G. K. Brown, P. R. Armstrong, and R. M. Beaudry. 1993. A portable instrument for measuring firmness of cherries and berries. ASAE Paper No. 93-6539. St. Joseph, Mich.: ASAE.

Waziri, A. and J. P. Mittal. 1993. Design related physical properties of selected agricultural products. Agricultural mechanization in ASIA, Africa and Latin America. 14 (1): 20-23. 


\section{الملخص العربي \\ خواص المرونة لثمار التمر \\ محمد إبراهيم غنيمي* محمد عبد الوهاب قاسم*}

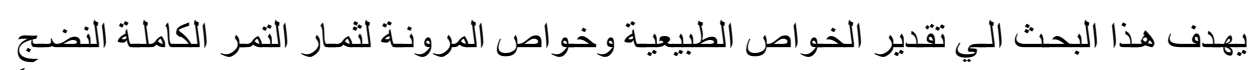

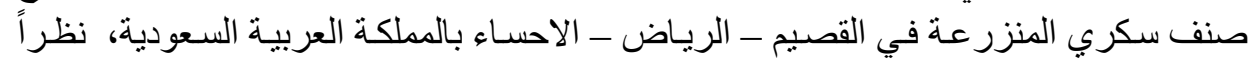
لانة يمكن من خلالها التعبير عن صلابة الثمرة.

وقد تم تقدير كل من الخو اص البعدية للثمرة، سمك اللحم، و المحتوى الرطوبى للثمرة، و الكثافة

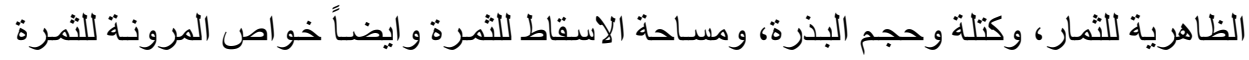

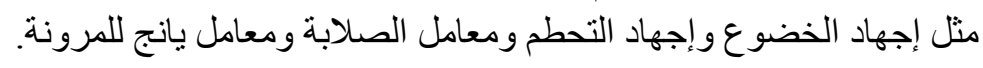
و قد بينت الاراسة ما يلي:

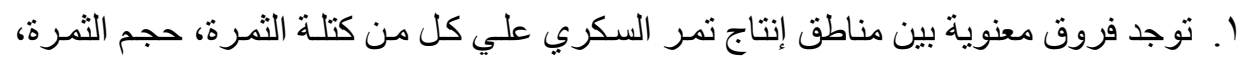

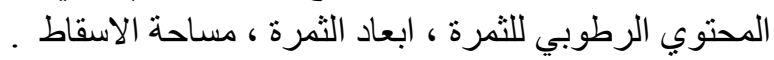

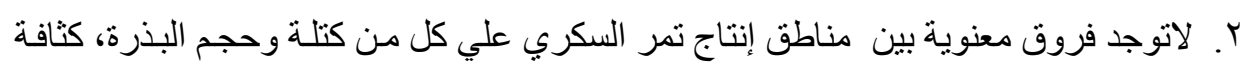

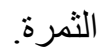

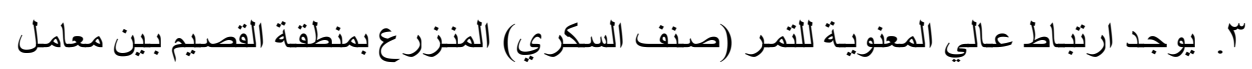
الصلابة و إجهاد الخضوع ويكون الارنونة لإنباط معنوي في باقي مناطق الدراسة.

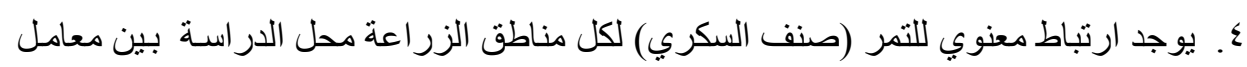
الصلابة و إجهاد التحطم.

○. وجود ارتباط تام بين معامل الصلابة ومعامل يانج للمرونة.

* استاذ الهنسسة الزراعية، كلية الزراعة، جامعة القاهرة. ** * استاذ الهندسة الزراعية المساعد، كلية الزراعة، جامعة الزعاهرة. 